\title{
Inequities in accessibility to and utilisation of maternal health services in Ghana after user-fee exemption: a descriptive study
}

\author{
John K Ganle ${ }^{1}$, Michael Parker ${ }^{1}$, Raymond Fitzpatrick ${ }^{2}$ and Easmon Otupiri ${ }^{3^{*}}$
}

\begin{abstract}
Introduction: Inequities in accessibility to, and utilisation of maternal healthcare services impede progress towards attainment of the maternal health-related Millennium Development Goals. The objective of this study is to examine the extent to which maternal health services are utilised in Ghana, and whether inequities in accessibility to and utilization of services have been eliminated following the implementation of a user-fee exemption policy, that aims to reduce financial barriers to access, reduce inequities in access, and improve access to and use of birthing services.
\end{abstract}

Methods: We analyzed data from the 2007 Ghana Maternal Health Survey for inequities in access to and utilization of maternal health services. In measuring the inequities, frequency tables and cross-tabulations were used to compare rates of service utilization by region, residence and selected socio-demographic variables.

Results: Findings show marginal increases in accessibility to and utilisation of skilled antenatal, delivery and postnatal care services following the policy implementation (2003-2007). However, large gradients of inequities exist between geographic regions, urban and rural areas, and different socio-demographic, religious and ethnic groupings. More urban women (40\%) than rural, 53\% more women in the highest wealth quintile than women in the lowest, 38\% more women in the best performing region (Central Region) than the worst (Upper East Region), and 48\% more women with at least secondary education than those with no formal education, accessed and used all components of skilled maternal health services in the five years preceding the survey. Our findings raise questions about the potential equity and distributional benefits of Ghana's user-fee exemption policy, and the role of non-financial barriers or considerations.

Conclusion: Exempting user-fees for maternal health services is a promising policy option for improving access to maternal health care, but might be insufficient on its own to secure equitable access to maternal health services in Ghana. Ensuring equity in access will require moving beyond user-fee exemption to addressing wider issues of supply and demand factors and the social determinants of health, including redistributing healthcare resources and services, and redressing the positional vulnerability of women in their communities.

Keywords: User-fee exemption, Maternal health, Access, Inequity, Ghana

\section{Introduction}

Lack of access and unequal access to essential maternal healthcare services have been identified as the main underlying causes of maternal deaths across the world, but specifically in Sub-Saharan Africa [1-5]. There is evidence to suggest that access to appropriate healthcare, especially skilled attendance at birth and

\footnotetext{
*Correspondence: easmono@yahoo.com

${ }^{3}$ Department of Community Health, School of Medical Sciences, Kwame

Nkrumah University of Science and Technology, Kumasi, Ghana

Full list of author information is available at the end of the article
}

timely referrals to emergency obstetric care, is strongly associated with substantial reductions in mortality and morbidity for both mother and newborn [6-9]. However, in many countries of sub-Saharan Africa including Ghana, few women use health facilities for birth [9]. While in high-income countries coverage of skilled birthing services is almost universal, in Africa only $47 \%$ of women give birth with a skilled care provider [7].

In Ghana, maternal mortality is the second largest cause of female deaths, and accounts for $14 \%$ of all female deaths [9]. In 2012, the World Health Organization (WHO) 
estimated that Ghana's maternal mortality ratio (MMR) was 350 maternal deaths per 100, 000 live births [10]. In addition, large and growing gradients of inequities in service accessibility and utilization have also been observed [11].

In an effort to achieve the Millennium Development Goal (MDG) 5 the government of Ghana introduced and is currently implementing a policy that provides free maternal health services to all women in all government, mission, and selected private health facilities [11,12]. The policy was first introduced in the 4 most deprived regions of the country (Northern, Upper East, Upper West, and Central) in 2003, and later extended to Ghana's remaining 6 regions in 2005 [13]. Under the policy, all women are entitled to a 'Maternal Benefit Package,' that includes 6 free antenatal visits; additional medically necessary visits captured as out patient department visits; free delivery at a health facility, including all delivery-related complications; 2 postnatal visits within 6 weeks; and care for the newborn up to three months.

The main argument in support of Ghana's user-fee exemption policy is that financial costs are a major barrier to skilled care and that the poor would not be able to afford to pay for the use of necessary services. The policy is therefore expected to reduce both the financial barriers to access and inequities in access, particularly access to supervised delivery services [14]. Indeed, within Sub-Saharan Africa, more than 11 other countries including Senegal, Burkina Faso, Mali, Kenya, Niger, and Tanzania have implemented similar policies [15-22]. Outside Africa, Nepal, Cambodia, China, Bangladesh, India, Pakistan and Bolivia are also implementing various cash transfer and user-fee exemption programmes for skilled maternal health services [15,23-28].

Despite the popularity of this new policy intervention, it is not clear to what extent skilled maternal healthcare services have become widely accessible and used in Ghana. It is also not clear whether variations in accessibility to and utilization of skilled care have been eliminated following the implementation of the policy in Ghana. To the authors' knowledge, evaluative studies of Ghana's user-fee exemption policy $[11,12]$ have not examined the equity dimension of access. One recent study observed that rigorous evaluations of whether the policy ensures universal access by eliminating inequities in access and service utilization are lacking [29]. The objective of this paper is to assess Ghana's user-fee exemption policy from an equity perspective, describing and exploring the extent to which it eliminates inequities in access to and use of maternal health services.

\section{Materials and methods Study design}

The study reported in this paper forms part of a larger, original study that the authors conducted to examine the effects of Ghana's user-fee exemption policy on women's maternity care seeking experience, equity of access, and barriers to accessibility and utilization of maternal and newborn healthcare services. The design of this larger study followed a mixed methods approach; involving analysis of a nationally representative retrospective household survey data in combination with qualitative exploration using data generated from anthropological research techniques of focus group discussions, in-depth interviews and structured field observations. In this paper, we focus on and report findings from the quantitative component of the study, which assessed inequities in accessibility to, and utilisation of maternal health services in Ghana.

\section{Study context}

Ghana is a lower middle-income West African country, with an estimated total population of 24,658, 823 [30]. Average life expectancy at birth is 60 (59 for male and 60.7 for females). Adult literacy - defined as the proportion of population aged 15 years or above who can read and write in English and a Ghanaian language - is 57.9\%. Ghana has a human development index (HDI) of 0.526 and a multi-dimensional poverty index of 0.14 . In 2005, about $30 \%$ of Ghana's population was estimated to live on less than US\$1 per day.

Like many lower-income countries, communicable diseases account for about two-thirds of out patient department visits in Ghana, with malaria being the main cause of outpatient morbidity [31]. In addition to the fact that maternal health outcomes continue to be poor in Ghana, we chose Ghana for this research because it is one of only a handful of countries in Africa to have actively started implementing both universal maternity care and health insurance policies at the national level. Because of this, Ghana is often seen as 'an example of global good practice' [32]. Despite this, maternal, neonatal and infant mortality ratios have remained persistently high in Ghana.

\section{Data sources}

The data for this study were extracted from the Ghana Maternal Health Survey 2007. The GMHS is the first nationally representative, high-quality population-based survey to collect information specifically on maternal health services accessibility and utilization since the implementation of the fee-free maternal health policy. The survey is a retrospective five-year (2003-2007) nationally representative survey of 10,858 households and 10,370 individual women aged 15-49 years. The survey was carried out to collect data to assess the level of maternal mortality in Ghana; identify specific causes of maternal and non-maternal deaths; and measure indicators of access to and utilization of maternal health services in Ghana. 
The survey was conducted in two phases. In phase I, a short nationally representative household survey questionnaire was administered to 240,000 households from 1,600 clusters or primary sampling units within the 10 administrative regions of Ghana. The 1,600 clusters were selected from a pre-existing list created for Ghana's 2000 Population and Housing Census. Out of the 240,000 households sampled in phase I, 226,209 households completed the questionnaire, with a $94.3 \%$ response rate. The purpose of the Phase I survey was to identify deaths to women aged 12-49 years in the 5 years preceding the survey. In Phase II, a verbal autopsy survey was conducted with households that reported one or more deaths of women aged 12-49 years. Apart from the verbal autopsy survey, Phase II also involved interviews with individual women aged 15-49 years from a total of 11,579 randomly selected households (independent of the households identified in Phase I as having experienced a female death). Of the 11,579 households, 10,994 were occupied at the time of the survey. However, 10,858 households were successfully interviewed, giving a response rate of $99 \%$. From the 10,858 interviewed households, a total of 10,627 women were identified as eligible for individual interview (i.e. women aged 15-49 years). Interviews were however completed for 10,370 women - 98\% response rate - using a questionnaire for individual women. The purpose of this Phase II survey was to collect information on key demographic and maternal and neonatal health indicators such as access and use of antenatal and emergency obstetric care in the event of a birth, abortion, or miscarriage. For the purposes of this paper, we used data from the interviews with individual women (i.e. data relating to access to and use of antenatal, maternity, and emergency obstetric care) generated in the second part of Phase II of the survey with the 10,370 individual women. Our analysis involved a total of 5,077 births - 4996 live births and 81 stillbirths that were recorded in the five years preceding the survey.

\section{Measuring inequities}

According to the International Society for Equity in Health, equity is the absence of potentially remediable, systematic differences in access and use of one or more aspects of maternal health services across socially, economically, demographically, or geographically defined population groups or subgroups [33]. This definition is useful for the discussion in this paper because it suggests that non-medical features of individuals or groups (such as their geographic location or ability to pay) should not determine their access to skilled maternity care services. It also implies a situation in which individuals or groups face equal or equivalent access and costs of utilization for equal or equivalent need [34].

In attempting to assess inequities in accessibility to, and utilisation of maternal health services, we used a three- step process outlined by Zere and colleagues [3,5,31]. These steps are: (i) identification of the care intervention whose distribution is to be measured; (ii) classification/ grouping of the population into different strata by a selected equity stratifier; and (iii) measuring the degree of inequality.

\section{The interventions}

The first step in assessing inequities involved definition of the interventions whose distributions are to be measured. These interventions included antenatal check-ups, tetanus toxoid immunization, delivery at a health facility, skilled attendance at birth, and caesarean sections (CS) during delivery, and postnatal check-ups. Access and equity of access to antenatal care was assessed by the timing, number of visits and type of care provider, and measured by the percentage of women from different socio-demographic backgrounds receiving these types of services. We assessed inequities in protection against tetanus by comparing the percentage of women from different socio-demographic backgrounds receiving the WHO recommended doses of at least two tetanus toxoid injection during their last live or still birth in the five years preceding the survey. Inequities in access to, and use of delivery care was measured by skilled attendant at delivery (i.e. percentage of births delivered by skilled providers including doctor, nurse, midwife, auxiliary midwife and community health officer), delivery in a health facility (i.e. percentage of births delivered in a public or private sector health facilities), delivery at public facility (i.e. percentage of births delivered in public sector health facilities), and home delivery (i.e. percentage of births delivered at home). We assessed inequities in access to and use of CS by measuring the percentage of live births in the five years preceding the survey delivered by $\mathrm{CS}$ according to our variable stratifiers. Within the literature, there is debate about the acceptable level at which a given population should be receiving CS [35-38]. Recently however, it has been argued that the proportion of deliveries by CS in a geographical area is a measure of access to, and use of, obstetric emergency care for averting maternal and newborn mortality, and that a population-based rate of $5-15 \%$ is considered as the acceptable level of CS to ensure the best outcomes for mothers and newborns [3]. Finally, we assessed inequities in postnatal care access by comparing whether a woman sought care after delivery and from whom across our variable stratifiers.

\section{The variables}

In the second step, we classified women by variable stratifiers against which accessibility to and utilisation of antenatal, delivery and postnatal care services was then assessed. These variables were mother's education, mother's age at birth, birth order, place of residence 
(urban/rural), geographical region of residence, wealth quintiles, religion and ethnicity. The survey data we used do not contain data on household income or consumption income. Therefore wealth index is used as a proxy. This wealth index is constructed from household ownership of assets and consumer goods (radio, television, telephone and refrigerator), dwelling characteristics, type of drinking water source, toilet facilities, electricity, wall and floor materials of house, cooking fuel, and means of transport. Each asset was assigned a weight (factor score) generated using the methods of principal component analysis [5], and the resulting asset scores standardized in relation to a normal distribution with a mean of zero and standard deviation of one (see [31]. From here, each household was given a score for each asset and these asset scores were then summed up for each household. Finally, individual women were ranked according to the total score of the household they came from; the sample was then divided into quintiles from lowest (one) to highest (five). Following this, a single asset index was developed for the whole sample, with no separate indices prepared for different regional or urban and rural populations.

We acknowledge that gauging the wealth status of households based on assets may be flawed because ownership of consumer goods is partly a function of taste and choice, and may therefore be independent of wealth [39]. Research has however shown that household assets often approximate the long-run economic status of households [40].

\section{Analytical method}

In the third and final step, we assessed access patterns, and equity in utilisation of the interventions we defined in the first step by analysing and comparing accessibility and utilization rates across the variable stratifiers using descriptive statistical tools. Within the healthcare literature, there is still considerable debate regarding the development of appropriate methods for assessing inequities in health and differentials in access among social groups [41]. However, Gulliford's recent work summarizes the different debates to suggest three main approaches, namely those depending on simple comparison of rates of access for different groups; those depending on the use of regression methods; and those that rely on the development of Gini-like coefficients [41]. Given that our study is mainly descriptive, we chose the first approach. Rates of access were compared for different population groups using both absolute measures (the difference in rates between the selected group and the reference group), and relative measures (the ratio of rates between selected and reference groups). We analysed all the data using the IBM SPSS Statistics data analysis software package (version 20), and MS Excel.

\section{Results}

\section{Descriptive statistics}

Figure 1 depicts the national coverage of access to, and use of antenatal care (ANC), delivery care (DC), and postnatal care (PNC) services in Ghana by skilled providers in percentage terms as at 2007 according to the GMHS.

At the national level, $96 \%$ of pregnant women in the five years preceding the survey (2003-2007) received at least one ANC from a skilled provider. In comparison with the baseline figure of 92\% reported in Ghana's 2003 Demographic and Health Survey, the number of births who received skilled ANC during the first five years (i.e. 2003-2007) of implementing the user-fee exemption policy increased by an average of $4 \%$. The $96 \%$ recorded for skilled ANC however dramatically decreased to 55\% each for skilled assistance during delivery and postnatal care following delivery. Compared with the baseline data in Ghana's 2003 Demographic and Health Survey again, skilled attendance at delivery went up from $47 \%$ in 2003 to $55 \%$ in 2007 . This represents a percentage change of $8 \%$. Similar incremental changes are observed for tetanus toxoid immunisation during pregnancy, delivery in a health facility, CS, and postnatal check-up. For example, the percentage of pregnant women who received at least two dosages of tetanus toxoid protection increased from $50 \%$ in 2003 to $62 \%$ in 2007 , while delivery in a health facility rose by $10 \%$ (i.e. from $46 \%$ in 2003 to $54 \%$ in 2007).

In terms of the distribution of access to and use of all components of maternal health services in the five years preceding the survey at the national level, only one-intwo women (48\%) accessed and used all three maternity care components, i.e. ANC, DC and PNC (Figure 2). About $4 \%$ of women did not receive a single component of maternity care at all, while $34 \%$ of women received ANC only. Similarly, $7 \%$ of the women received both ANC and DC or ANC and PNC only.

Although the above statistics are useful in giving a broad understanding of the levels of skilled maternity care coverage at the national level, what is not easily discernable through these national level statistics is that large gradients of inequities in complete coverage of maternity care service accessibility and utilization exist for the different categories of respondents (Figures 3 and 4). For example, less educated women, rural women and women in poorer households were less likely to receive complete maternity care than urban, more educated and wealthier women. Complete coverage of maternity care services also declines with birth order from $58 \%$ for first births to $34 \%$ among births of six or higher, and is highest among mothers aged 20-34 years. In comparative regional terms, complete coverage of maternity care ranged from a high of $62 \%$ in the Central region to a 


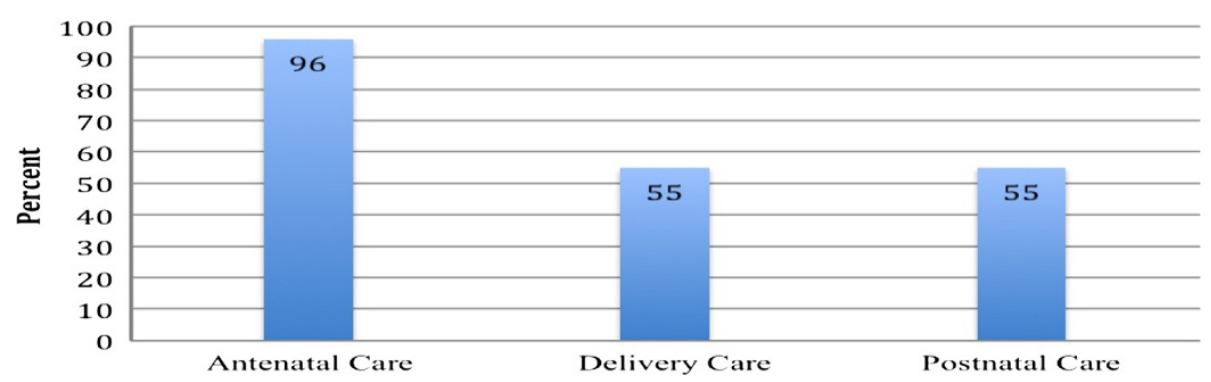

Figure 1 Percentage distribution of coverage of ANC, DC and PNC by skilled provider for the most recent live or stillbirth in the 5 years preceding the survey.

low of $24 \%$ in the Northern region. In other words, in the five years preceding the study, whereas $62 \%$ of all births in the Central region received all the three main maternity care components, only $24 \%$ of births in the Northern region did. But the inequities in completeness of maternity care access between geographic regions, urban and rural areas, and different socio-demographic groupings appear to be reproduced by inequities in the individual maternity care interventions. For this reason, the next sections focus on examining the nature of these access and utilisation inequities separately for ANC, tetanus immunization, DC, delivery at a health facility, skilled attendance at delivery, caesarean sections (CS), and PNC.

\section{Inequities in access and use of ANC services}

Tables 1 and 2 show the distribution of ANC service accessibility and utilization by women who either had a live or stillbirth in the five years preceding the survey according to various background characteristics. Generally, inequities in levels of antenatal care access among subgroups of women in Ghana appear to be smaller, at least in the five years preceding the survey. Yet, as Table 1 shows, the percentage difference between antenatal care from a skilled provider (doctor) for the best performing region (Greater Accra, 46\%) and the worst (Upper East, 2\%) is 44\%. ANC access was also more common among mothers who have had a live birth (96\%) than among mothers who have had a stillbirth $(88 \%)$, and is highest among births to mothers aged 20 years or below and among first order births (Table 1 ).

Less surprisingly, the frequency of ANC visits is higher in urban than rural areas, with $89 \%$ of urban women seeking care at least 4 times, compared with $70 \%$ of rural women (Table 2). Differences by region ranged from a low median of 3.4 months in the Upper West to a high of 4.3 months in the Northern region for seeking initial antenatal care. Antenatal care access is also higher among women with secondary or higher level of education (7.9) than women with no education (5.3), and among those in the highest wealth quintile (8.3) than those in the lowest quintile (4.9).

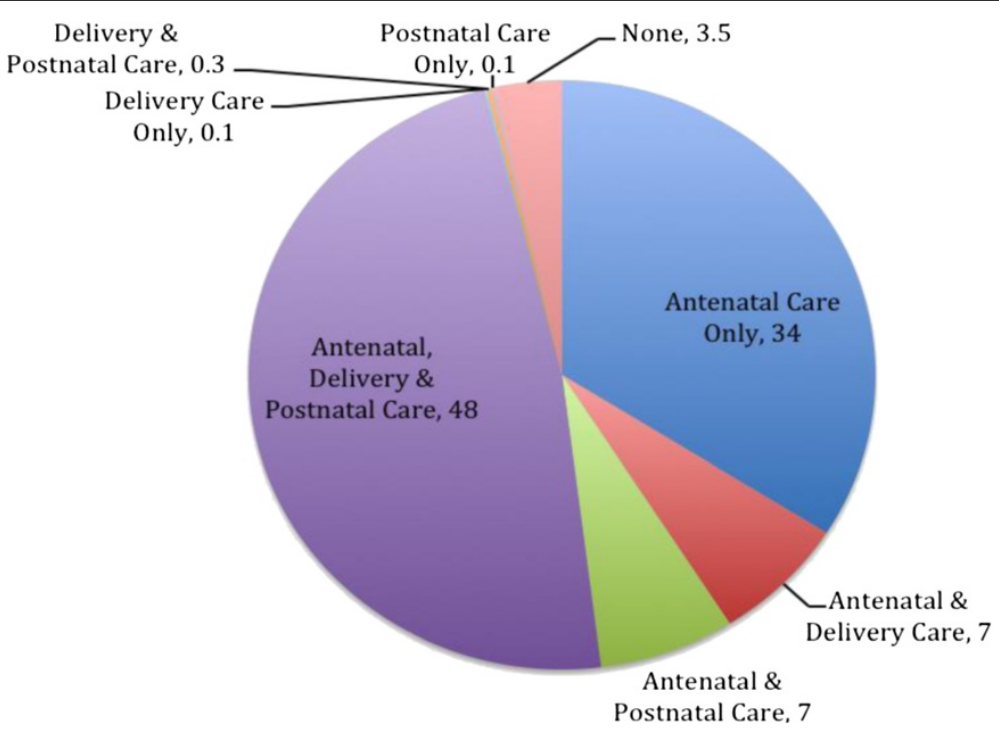

Figure 2 Percentage distribution of completeness of access to and use of skilled maternity care services in Ghana. 


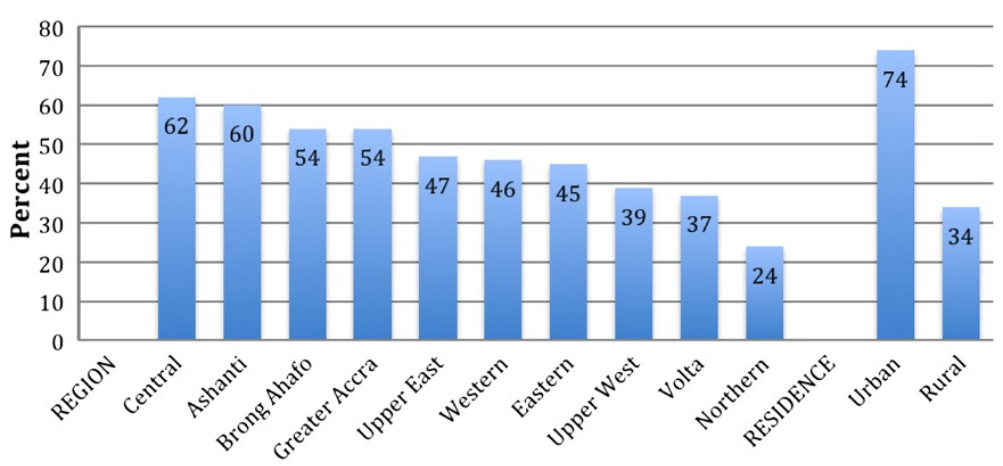

Figure 3 Per cent distribution of most recent live or stillbirth in the five years preceding the survey for which skilled ANC, DC, and PNC were received by region and residence.

Inequities in access to tetanus toxoid immunization

Tables 3 and 4 show that nearly $62 \%$ of the women who took part in the survey received at least two doses of tetanus toxoid during pregnancy for their most recent birth. Similarly about four-in-five women (79\%) were protected against tetanus for their last birth. There are however important differences in access and utilisation levels between different regions, wealth groups, and ethnic and religious groups (Table 3 and 4$)$.

\section{Inequities in access and use of delivery care services}

Figure 5 shows that skilled providers (i.e. a doctor, nurse/midwife or auxiliary midwife) delivered just a little over one-in-two births (55\%) in Ghana. However, this national statistic tells little about the fact that pervasive access inequities exist between women of different socio-demographics as can be observed in Tables 5 and 6. For instance, the number of births to women in the Greater Accra, Ashanti and Western regions that were delivered in health facilities with a medical doctor in attendance was twice the number of births to women in the Northern and Upper regions (Table 5). Similarly, $88 \%$ of births to women with at least secondary education occurred in a health facility, compared with $31 \%$ of births to women with no education, while $92 \%$ of women in the highest wealth quintile had institutional deliveries, compared with $27 \%$ of women in the lowest wealth quintile (Table 6). Also more births to women living in urban areas took place in a health facility compared to births to women living in rural Ghana. For instance, four-in-five births in Greater Accra were delivered in a health facility, compared with one-in-four births in the Northern Region.

Two other variables against which we assessed equity of access to skilled delivery care are religion and ethnicity. As shown in Table 7 , the range for consultation of a health worker for prenatal or delivery care among religious groups is 50.9 percentage points; from a low of $24 \%$ among births to women of traditional African religious orientation to $75 \%$ among births to Pentecostal and Charismatic Christians. Overall, women professing traditional/spiritualist and Moslem religious faiths accessed and used less of health facility delivery

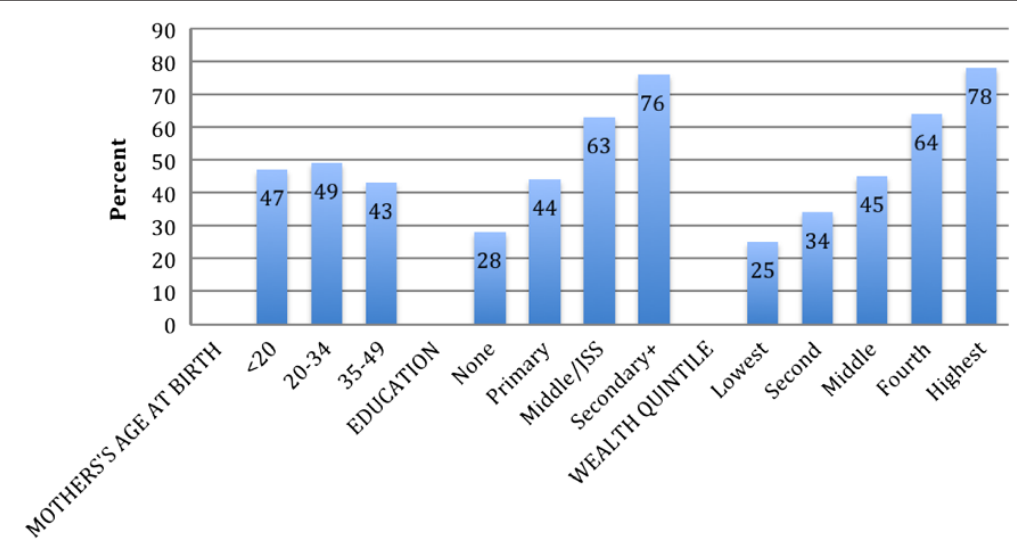

Figure 4 Per cent distribution of most recent live birth or still birth in the 5 years preceding the survey for which ANC, DC \& PNC were received by mother's age at birth, level of education, and wealth. 
Table 1 Per cent distribution of women who had a live or stillbirth in the five years preceding the survey by whether mother received ANC from a skilled provider

\begin{tabular}{lllllll}
\hline $\begin{array}{l}\text { Background } \\
\text { characteristic }\end{array}$ & $\begin{array}{l}\text { Received Doctor } \\
\text { any ANC }\end{array}$ & $\begin{array}{l}\text { Nurse/midwife/ } \\
\text { auxiliary midwife }\end{array}$ & $\begin{array}{l}\text { Trained } \\
\text { traditional } \\
\text { birth } \\
\text { attendant }\end{array}$ & $\begin{array}{l}\text { Untrained } \\
\text { traditional } \\
\text { birth } \\
\text { attendant }\end{array}$ & $\begin{array}{l}\text { Other No one Missing } \\
\text { attalal }\end{array}$ & $\begin{array}{l}\text { Percent } \\
\text { receiving ANC } \\
\text { from a skilled } \\
\text { provider }\end{array}$ \\
\hline
\end{tabular}

\section{Birth outcome}

$\begin{array}{llll}\text { Live birth } & 96.7 & 18.5 & 77.8 \\ \text { Stillbirth } & 87.9 & 23.1 & 64.7\end{array}$
provider

Age of mother

\section{at birth}

$\begin{array}{llll}<20 & 97 & 14.7 & 82.1 \\ 20-34 & 96.8 & 19.2 & 77.2 \\ 35-49 & 95.2 & 18.1 & 76.6\end{array}$

$\begin{array}{ll}0.1 & 0 \\ 0.2 & 0.1 \\ 0.3 & 0.1\end{array}$

$\begin{array}{lll}0.1 & 3.2 & 0 \\ 0 & 10.2 & 2\end{array}$

$\begin{array}{ll}100 & 96.3 \\ 100 & 87.9\end{array}$

4,847

81

Birth order

$\begin{array}{llll}1 & 98.6 & 20.7 & 77.7 \\ 2-3 & 97.2 & 20.5 & 76.4 \\ 4-5 & 96.9 & 18.3 & 77.8 \\ 6+ & 92.4 & 12.7 & 79.4\end{array}$

Residence

$\begin{array}{llll}\text { Rural } & 95.4 & 12.1 & 82.8 \\ & 98.7 & 30.8 & 67.6\end{array}$

Education

$\begin{array}{llll}\text { None } & 93.5 & 11.1 & 82.1 \\ \text { Primary } & 96.7 & 18.2 & 77.9 \\ \text { Middle/JSS } & 98.6 & 21.3 & 76.9 \\ \text { Secondary+ } & 99.5 & 40.8 & 58.6\end{array}$

\section{Region}

$\begin{array}{llll}\text { Ashanti } & 97.9 & 27.6 & 69.8 \\ \text { Brong Ahafo } & 98 & 11.4 & 86.3 \\ \text { Central } & 97.8 & 13.2 & 84.4 \\ \text { Eastern } & 97.2 & 16.9 & 79.4 \\ \text { Greater Accra } & 96.4 & 45.7 & 50.1 \\ \text { Northern } & 91.7 & 7.6 & 84 \\ \text { Volta } & 96.4 & 10.7 & 85.7 \\ \text { Upper East } & 98.7 & 2.4 & 95.9 \\ \text { Upper West } & 94.3 & 3.4 & 90.9 \\ \text { Western } & 97 & 27.2 & 69.2\end{array}$

Wealth

quintile

\begin{tabular}{|c|c|c|c|c|c|c|c|c|c|c|c|}
\hline Lowest & 93.1 & 7.9 & 84.8 & 0.2 & 0.3 & 0.1 & 6.9 & 0 & 100 & 92.7 & 1,074 \\
\hline Second & 94.9 & 9.4 & 85 & 0.3 & 0.1 & 0.1 & 5 & 0.1 & 100 & 94.4 & 1,061 \\
\hline Middle & 98.2 & 16.2 & 81.7 & 0.3 & 0 & 0.2 & 1.8 & 0 & 100 & 97.9 & 975 \\
\hline Fourth & 98.1 & 25.5 & 72.2 & 0.2 & 0 & 0 & 1.5 & 0.3 & 100 & 97.7 & 983 \\
\hline Highest & 99 & 38.2 & 60.6 & 0 & 0.2 & 0.1 & 0.6 & 0.4 & 100 & 98.7 & 835 \\
\hline Total & 96.5 & 18.5 & 77.6 & 0.2 & 0.1 & 0.1 & 3.3 & 0.2 & 100 & 96.1 & 4,928 \\
\hline
\end{tabular}


Table 2 Per cent distribution of number of ANC visits and median number of visits for the most recent live birth or stillbirth in the five years preceding the survey

\begin{tabular}{|c|c|c|c|c|c|c|c|c|}
\hline Background characteristic & 0 & 1 & $2-3$ & $4+$ & Don't know/missing & Total & Median number of visits & Number of births \\
\hline \multicolumn{9}{|l|}{ Birth outcome } \\
\hline Live birth & 3.2 & 3.4 & 16 & 77 & 0.5 & 100 & 5.9 & 4,847 \\
\hline Stillbirth & 10.2 & 9.7 & 13.8 & 63.3 & 3.1 & 100 & 5.6 & 81 \\
\hline \multicolumn{9}{|l|}{ Age of mother at birth } \\
\hline$<20$ & 3 & 3.9 & 20.9 & 71.7 & 0.5 & 100 & 5.2 & 534 \\
\hline $20-34$ & 3 & 3 & 14.9 & 78.5 & 0.5 & 100 & 6.1 & 3,391 \\
\hline $35-49$ & 4.4 & 4.8 & 16.6 & 73.3 & 0.8 & 100 & 5.7 & 1,003 \\
\hline \multicolumn{9}{|l|}{ Birth order } \\
\hline 1 & 1.2 & 2.9 & 14 & 81.5 & 0.4 & 100 & 6.2 & 1,051 \\
\hline $2-3$ & 2.7 & 2.9 & 14.2 & 79.6 & 0.5 & 100 & 6.1 & 1,769 \\
\hline $4-5$ & 2.9 & 3.4 & 16.2 & 76.8 & 0.6 & 100 & 65 & 1,161 \\
\hline $6+$ & 7.3 & 5.1 & 20.8 & 66 & 0.8 & 100 & 2 & 948 \\
\hline \multicolumn{9}{|l|}{ Residence } \\
\hline Rural & 4.6 & 4.5 & 20.3 & 70.3 & 0.4 & 100 & 5.3 & 3 \\
\hline Urban & 0.9 & 1.5 & 7.5 & 89.1 & 1 & 100 & 7.3 & 1 \\
\hline \multicolumn{9}{|l|}{ Education } \\
\hline None & 6.3 & 5.2 & 19.2 & 68.6 & 0.8 & 100 & 5.3 & 1,678 \\
\hline Primary & 2.8 & 4.4 & 21.1 & 70.5 & 1.1 & 100 & 5.4 & 1,102 \\
\hline Middle/JSS & 1.4 & 1.7 & 11.8 & 85 & 0.1 & 100 & 6.5 & 1,797 \\
\hline Secondary+ & 0.5 & 1 & 5.2 & 92.9 & 0.4 & 100 & 7.9 & 350 \\
\hline \multicolumn{9}{|l|}{ Region } \\
\hline Ashanti & 1.9 & 3.1 & 11.5 & 83.2 & 0.3 & 100 & 6.6 & 922 \\
\hline Brong Ahafo & 2 & 4.3 & 15.8 & 77.7 & 0.1 & 100 & 5.9 & 564 \\
\hline Central & 2.2 & 3.1 & 10.1 & 84.3 & 0.2 & 100 & 6.2 & 479 \\
\hline Eastern & 2.7 & 4.3 & 20.1 & 72.8 & 0.1 & 100 & 5.6 & 567 \\
\hline Greater Accra & 3.2 & 1.9 & 12.2 & 80.9 & 1.7 & 100 & 7.5 & 470 \\
\hline Northern & 8.2 & 4.7 & 14.8 & 71.6 & 0.8 & 100 & 5.5 & 699 \\
\hline Volta & 3.5 & 5.9 & 29.9 & 60.6 & 0.1 & 100 & 4.8 & 451 \\
\hline Upper East & 1.3 & 0 & 10.6 & 87.6 & 0.6 & 100 & 5.8 & 225 \\
\hline Upper West & 5.7 & 2.1 & 20 & 68.9 & 3.5 & 100 & 5.9 & 152 \\
\hline Western & 2.5 & 1.5 & 19.3 & 76.1 & 0.5 & 100 & 5.5 & 400 \\
\hline \multicolumn{9}{|l|}{ Wealth quintile } \\
\hline Lowest & 6.9 & 7.2 & 23.6 & 61.9 & 0.5 & 100 & 4.9 & 1,074 \\
\hline Second & 5 & 4.3 & 20.8 & 69.4 & 0.5 & 100 & 5.2 & 1,061 \\
\hline Middle & 1.8 & 2.6 & 18.7 & 76.7 & 0.2 & 100 & 5.5 & 975 \\
\hline Fourth & 1.5 & 1.4 & 9.9 & 86.5 & 0.5 & 100 & 6.7 & 983 \\
\hline Highest & 0.6 & 0.9 & 3.7 & 93.7 & 1.1 & 100 & 8.3 & 835 \\
\hline Total & 3.3 & 5.3 & 15.9 & 76.7 & 0.6 & 100 & 5.9 & 4,928 \\
\hline
\end{tabular}

services compared with Christians. As regards ethnicity, few Hausa (13\%), Ga/Dangme (22\%) and Akan (23\%) women gave birth at home compared to women of the Ewe (44\%), Guan (57\%), Grussi (60\%), Mole-Dagbani (61\%) and Gruma (66\%) ethnic extractions.
Inequities in access and use of caesarean sections during delivery

Tables 5 and 8 contain information about access and use of caesarean section (CS) services among women who had a live or stillbirth in the five years preceding the 
Table 3 Tetanus toxoid immunization during pregnancy for the last birth in the five years preceding the survey

\begin{tabular}{llll}
\hline Background & $\begin{array}{l}\text { Percent receiving } \\
\text { characteristic }\end{array}$ & $\begin{array}{l}\text { Percent whose } \\
\text { two or more } \\
\text { injections during } \\
\text { last pregnancy }\end{array}$ & $\begin{array}{l}\text { last birth was } \\
\text { protected against } \\
\text { neonatal tetanus }\end{array}$
\end{tabular}

Birth outcome

Live birth

61.9

Stillbirth

47.3

79.6

4,847

Mother's age

at birth

$<20$

20-30

59.5

62.2

61.1

69.4

81

35-49

Birth order

$0-1$

$2-3$

66.2

60.4

4-5

60.3

$6+$

60.8

Residence

Urban

64.9

Rural

60

Region

Ashanti

Brong Ahafo 59.5

Central $\quad 64.6$

Eastern $\quad 57.7$

Greate Accra 57.6

Northern $\quad 67$

Volta $\quad 54.6$

Upper East $\quad 73.7$

Upper West 71.4

Western

62.4

Education

None $\quad 60.6$

Primary $\quad 58.5$

Middle/JSS $\quad 63.2$

Secondary+ $\quad 69.2$

Wealth quintile

$\begin{array}{ll}\text { Lowest } & 61.6 \\ \text { Second } & 57.3 \\ \text { Middle } & 61.2 \\ \text { Fourth } & 62 . \\ \text { Highest } & 67.6 \\ \text { Total } & \mathbf{6 1 . 7}\end{array}$

Total

61.7

72.4

80.4

79.9

73.8

81.4

81.8

79.1

82.7

77.7

85.5

80.8

84.9

78.4

74

69.8

78.5

77.7

79.1

83.5

72

80.1

84.8

84.8

74.1

75.5

81.6

82.6

85

79.4 survey. There are large disparities for this indicator too. Whereas the percentage of women delivering by CS is as high as $13.1 \%$ in the Greater Accra region for example, the Northern and Upper East regions recorded 3.1\% and $2.4 \%$ respectively. Also whereas $11.3 \%$ of urban women used CS during their last birth in the five years preceding the survey, only $4 \%$ of rural women did (see Table 5). The differences in terms of wealth quintiles are also striking: $15.4 \%$ for the highest and $2.7 \%$ for the lowest. First time mothers are also more than twice (9.4\%) likely to use deliver by CS compared to 6th order and above births (4.2\%). There are also striking access differentials between different religious and ethnic groups. Whereas $15 \%$ of Presbyterian Christians accessed and used CS services, only $6 \%$ of women professing traditional/spiritualist religion did. Moslem women also accessed and used CS services less compared with their Christian counterparts. In terms of accessibility and utilization according to ethnic affiliation, 16\% (the highest) of Ewe and only $6 \%$ (the lowest) of Gruma women delivered their last baby by CS.

\section{Inequities in access to and use of postpartum care services}

One intervention for which equity assessment can also be made in the context of Ghana's user-fee exemption policy is postpartum care. Table 9 shows the percentage distribution by timing of first postnatal check-up among women with a live or stillbirth in the five years preceding the survey by birth outcome, place of delivery, residence, region, and wealth, while Table 10 shows the per cent distribution of whether postnatal care was received among women with a live or stillbirth in the five years preceding the survey, according to religion and ethnicity. About 76\% (3 in 4) of women reported receiving postdelivery care for themselves and their babies during their last birth in the five years preceding the survey. However, a cursory analysis of Tables 9 and 10 reveals substantial differences and/ or inequities. Broadly, the differences in postpartum care access by demographic, socio-economic and residential background attributes mirror differences already seen for ANC and DC.

\section{Discussion \\ Main results}

This paper has attempted to assess the extent and nature of inequities in access to and use of maternal health services in Ghana after user-fee exemption for maternal health services. Results from our descriptive statistical analysis of survey data indicated that the implementation of the exemption policy in Ghana appeared to have been accompanied by marginal increases in the proportion of women who accessed and used antenatal, delivery, and postnatal care services from skilled health professional 
Table 4 Tetanus toxoid immunization during pregnancy for the last live birth or stillbirth in the five years preceding the survey by religion and ethnicity

\begin{tabular}{|c|c|c|c|c|c|}
\hline $\begin{array}{l}\text { Background } \\
\text { characteristic }\end{array}$ & $\begin{array}{l}\text { Had tetanus } \\
\text { toxoid } \\
\text { injection }\end{array}$ & $\begin{array}{l}\text { No tetanus } \\
\text { toxoid } \\
\text { injection }\end{array}$ & $\begin{array}{l}\text { Don't } \\
\text { know }\end{array}$ & Total & $\begin{array}{l}\text { Number } \\
\text { of births }\end{array}$ \\
\hline \multicolumn{6}{|l|}{ Religion } \\
\hline Catholic & 88.7 & 10.8 & 0.3 & 100 & 694 \\
\hline Protestant & 90 & 10 & 0 & 100 & 80 \\
\hline Methodist & 93.4 & 6 & 0.6 & 100 & 348 \\
\hline Presbyterian & 91.2 & 8.8 & 0 & 100 & 317 \\
\hline $\begin{array}{l}\text { Pentecostal/ } \\
\text { charismatic }\end{array}$ & 90.2 & 9 & 0.8 & 100 & 1404 \\
\hline Other Christian & 87.8 & 11.8 & 0.4 & 100 & 836 \\
\hline Moslem & 92.5 & 7.5 & 0 & 100 & 896 \\
\hline $\begin{array}{l}\text { Traditional/ } \\
\text { spiritualist }\end{array}$ & 72.5 & 27.5 & 0 & 100 & 207 \\
\hline No religion & 85.7 & 14.3 & 0 & 100 & 293 \\
\hline Other & 100 & 0 & 0 & 100 & 1 \\
\hline \multicolumn{6}{|l|}{ Ethnicity } \\
\hline Akan & 91.8 & 7.7 & 0.6 & 100 & 2248 \\
\hline Ga/Dangme & 85.9 & 13.9 & 0.2 & 100 & 404 \\
\hline Ewe & 85.6 & 14.3 & 0.2 & 100 & 644 \\
\hline Guan & 86.6 & 13.4 & 0 & 100 & 119 \\
\hline Mole-Dagbani & 88.9 & 11.1 & 0 & 100 & 548 \\
\hline Grussi & 91.9 & 7.7 & 0.4 & 100 & 246 \\
\hline Gruma & 84.3 & 15.5 & 0.3 & 100 & 343 \\
\hline Hausa & 95.2 & 4.8 & 0 & 100 & 62 \\
\hline Other & 88.6 & 11.4 & 0 & 100 & 463 \\
\hline Total & 89.3 & 10.3 & 0.3 & 100 & 5077 \\
\hline
\end{tabular}

Note: Total includes 149 women with missing information on tetanus toxoid immunization. in a health facility setting. Our study has however revealed important discrepancies in access to and use of maternal health services that should not be underestimated. Except for ANC, our findings showed that the proportion of women who had access to delivery and post-delivery care was still low and even considerably lower for women of certain socio-demographic groupings such as the poor. For example $45 \%$ of births in the last five years before the survey took place at home without skilled attendance. Similarly, $45 \%$ of the women who gave birth during the same period did not receive any form of postpartum care. Thus our analysis has shown that substantial differences in access and service use characterized Ghana's maternal health delivery system.

It is difficult to disentangle the effect of other factors than the user-fee exemption policy on the observed increases in service uptake. This is not only because the universal nature of Ghana's user-fee exemption policy made it hard to conduct robust comparative analysis in our study, but also the data needed to conduct such analysis did not exist at the time of this research. Consequently, correlation here must not mean causation. Nevertheless, our findings support previous research in Ghana $[11,29]$ and elsewhere $[42,43]$ that found similar incremental changes in access to, and use of maternal health services following the abolition of user-fees for maternal health services.

Again, it is difficult to make any judgement about the relationship between Ghana's free maternal health policy and the observed inequities in access to and use of maternal health services from our study. It is plausible that access inequities improved from an even more inequitable distributive baseline following the implementation of the policy or vice versa. The lack of relevant comparable data before the introduction of the policy did not permit this hypothesis to be further explored in our research. This notwithstanding, our findings are consistent with previous studies in Mali [20] and Kenya [22] which

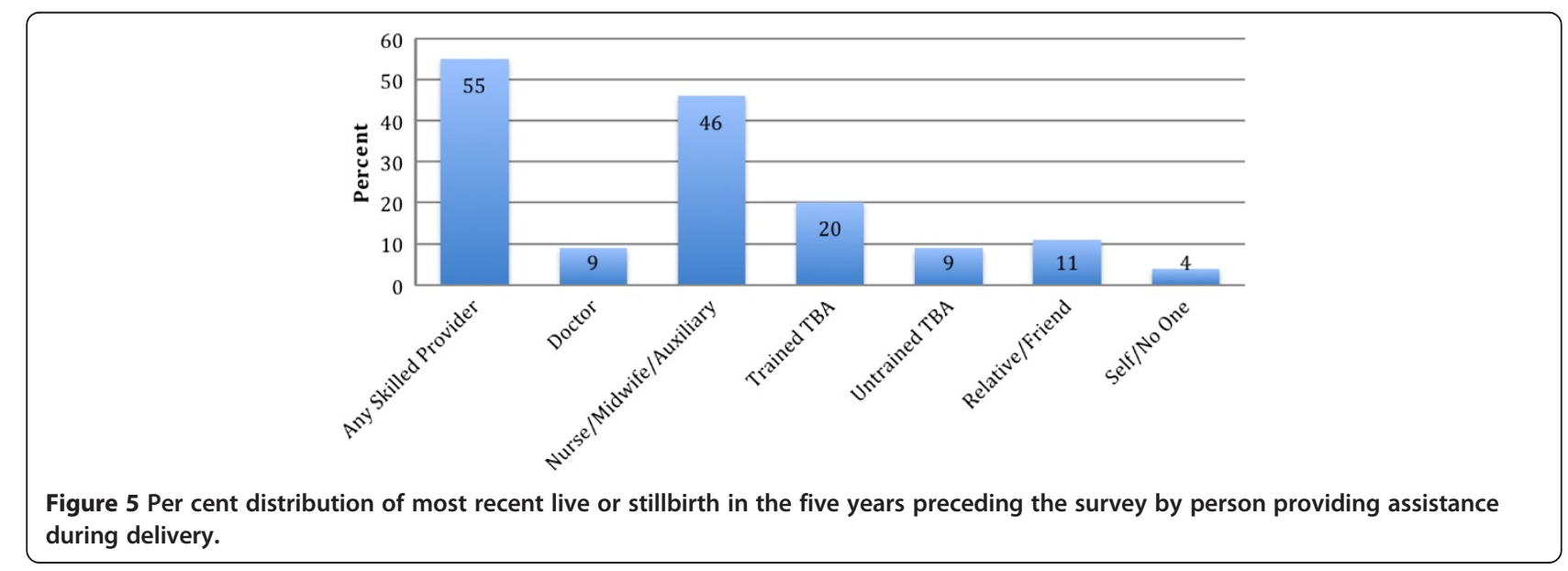


Table 5 Per cent distribution of live or stillbirth in the five years preceding the survey by person providing assistance during delivery

\begin{tabular}{|c|c|c|c|c|c|c|c|c|c|c|c|c|}
\hline $\begin{array}{l}\text { Background } \\
\text { characteristic }\end{array}$ & Doctor & $\begin{array}{l}\text { Nurse/ } \\
\text { midwife/ } \\
\text { auxiliary } \\
\text { midwife }\end{array}$ & $\begin{array}{l}\text { Trained } \\
\text { traditional } \\
\text { birth } \\
\text { attendant }\end{array}$ & $\begin{array}{l}\text { Untrained } \\
\text { traditional } \\
\text { birth } \\
\text { attendant }\end{array}$ & $\begin{array}{l}\text { Relative/ } \\
\text { Friend }\end{array}$ & $\begin{array}{l}\text { No } \\
\text { one }\end{array}$ & Other & Missing & Total & $\begin{array}{l}\text { Percent } \\
\text { delivered by } \\
\text { a skilled } \\
\text { provider }\end{array}$ & $\begin{array}{l}\text { Percent } \\
\text { delivered by } \\
\text { CS }\end{array}$ & $\begin{array}{l}\text { Number } \\
\text { of births }\end{array}$ \\
\hline
\end{tabular}

\section{Birth outcome}

$\begin{array}{lllllllllllll}\text { Live birth } & 8.9 & 46.1 & 20.3 & 9.5 & 11.2 & 3.7 & 0 & 0.3 & 100 & 55 & 6.3 & 4847 \\ \text { Stillbirth } & 28.6 & 40.8 & 11.5 & 1.6 & 7.5 & 5.3 & 2.8 & 2 & 100 & 69.3 & 18.9 & 81\end{array}$

Age of mother

at birth

$\begin{array}{lllllllllllll}<20 & 8.6 & 46.5 & 22.2 & 9.1 & 11.7 & 1.9 & 0 & 0 & 100 & 55.1 & 6.5 & 534 \\ 20-34 & 9.3 & 47.4 & 19.6 & 9.4 & 11 & 3.1 & 0 & 0.2 & 100 & 56.7 & 6.6 & 3391 \\ 35-49 & 9.2 & 41.1 & 21 & 9.4 & 11.5 & 6.8 & 0.2 & 0.9 & 100 & 50.2 & 6.3 & 1003\end{array}$

Birth order

$\begin{array}{lllllllllllll}1 & 12.4 & 54.6 & 16.8 & 7.6 & 7 & 1.1 & 0 & 0.5 & 100 & 67 & 9.4 & 1051 \\ 2-3 & 9.2 & 49.2 & 19.5 & 8.6 & 11.3 & 2.1 & 0 & 0.1 & 100 & 58.4 & 6.4 & 1769 \\ 4-5 & 8.1 & 43.8 & 21.1 & 9.8 & 12.6 & 4.2 & 0.1 & 0.2 & 100 & 51.9 & 5.9 & 1161 \\ 6+ & 6.9 & 33.3 & 23.8 & 12.1 & 13.8 & 9 & 0.2 & 0.8 & 100 & 40.3 & 4.2 & 948\end{array}$

Residence

$\begin{array}{lllllllllllll}\text { Rural } & 5.4 & 33.8 & 27.4 & 13 & 15.1 & 4.8 & 0.1 & 0.3 & 100 & 39.2 & 4 & 3781 \\ \text { Urban } & 16.5 & 69.5 & 6.1 & 2.3 & 3.6 & 1.5 & 0 & 0.5 & 100 & 86 & 11.3 & 1683\end{array}$

Education

$\begin{array}{lllllllllllll}\text { None } & 4 & 28.3 & 25.8 & 16.6 & 18.5 & 6.1 & 0.1 & 0.5 & 100 & 32.4 & 3.4 & 1678 \\ \text { Primary } & 8.6 & 43.6 & 21.8 & 9.3 & 11.8 & 4.2 & 0.1 & 0.6 & 100 & 52.2 & 6.4 & 1102 \\ \text { Middle/JSS } & 11.8 & 60 & 16.3 & 4.1 & 5.9 & 1.8 & 0 & 0.1 & 100 & 71.7 & 7.9 & 1797 \\ \text { Secondary+ } & 22.6 & 66.6 & 7.4 & 1.5 & 1.4 & 0.5 & 0 & 0 & 100 & 89.2 & 14.6 & 350\end{array}$

Region

\begin{tabular}{|c|c|c|c|c|c|c|c|c|c|c|c|c|}
\hline Ashanti & 13.8 & 54.8 & 13.2 & 6.2 & 9 & 2.6 & 0.1 & 0.2 & 100 & 68.7 & 8.6 & 922 \\
\hline Brong Ahafo & 6.3 & 50.6 & 18.2 & 7.9 & 11.1 & 5.6 & 0 & 0.3 & 100 & 56.9 & 5.1 & 564 \\
\hline Central & 6.1 & 57.8 & 25 & 4.5 & 2.8 & 3.7 & 0 & 0.2 & 100 & 63.8 & 6.3 & 479 \\
\hline Eastern & 8.8 & 48.9 & 22.2 & 8.3 & 8.2 & 3.6 & 0 & 0.1 & 100 & 57.7 & 8.4 & 567 \\
\hline Greater Accra & 24.2 & 55.1 & 10.2 & 2.9 & 3.7 & 3.6 & 0 & 0.4 & 100 & 79.3 & 13.1 & 470 \\
\hline Northern & 4.8 & 22.5 & 21 & 24.5 & 21 & 5.6 & 0.3 & 0.2 & 100 & 27.3 & 3.1 & 699 \\
\hline Volta & 2.7 & 38.7 & 22.4 & 5.5 & 26.9 & 3.8 & 0 & 0.1 & 100 & 41.3 & 3.5 & 451 \\
\hline Upper East & 2.2 & 45 & 31.6 & 9.7 & 9.3 & 1.5 & 0 & 0.8 & 100 & 47.1 & 2.4 & 225 \\
\hline Upper West & 3.2 & 39 & 33.3 & 5.7 & 13.8 & 4.6 & 0 & 0.4 & 100 & 42.2 & 3.7 & 152 \\
\hline Western & 10.5 & 43.1 & 26.3 & 12.8 & 4.4 & 1.5 & 0 & 1.5 & 100 & 53.7 & 6.1 & 400 \\
\hline \multicolumn{13}{|l|}{ Vealth quintile } \\
\hline Lowest & 3.2 & 25.2 & 26 & 17.6 & 21.5 & 6.3 & 0 & 0.2 & 100 & 28.4 & 2.7 & 1074 \\
\hline Second & 4.6 & 32.3 & 28.8 & 13.3 & 15.3 & 5.1 & 0.3 & 0.2 & 100 & 36.9 & 3.1 & 1061 \\
\hline Middle & 6.4 & 46.5 & 24.8 & 8.5 & 9.7 & 3.9 & 0 & 0.2 & 100 & 52.9 & 4.7 & 975 \\
\hline Fourth & 12.5 & 63 & 13.7 & 3.5 & 5.3 & 1.5 & 0 & 0.6 & 100 & 75.5 & 8.7 & 983 \\
\hline Highest & 22.1 & 69.6 & 3.8 & 1.6 & 1.4 & 1 & 0 & 0.5 & 100 & 91.8 & 15.4 & 835 \\
\hline otal & 9.2 & 46 & 20.1 & 9.4 & 11.2 & 3.7 & 0.1 & 0.3 & 100 & 55.2 & 6.5 & 4928 \\
\hline
\end{tabular}


Table 6 Per cent distribution of most recent live or stillbirths in the five years preceding the survey by place of delivery

\begin{tabular}{|c|c|c|c|c|c|c|c|c|}
\hline Background characteristic & Public health facility & Private health facility & Home & Other & Missing & Total & $\begin{array}{l}\text { Percent delivered } \\
\text { in a health facility }\end{array}$ & $\begin{array}{l}\text { Number } \\
\text { of births }\end{array}$ \\
\hline \multicolumn{9}{|l|}{ Birth outcome } \\
\hline Live birth & 42.9 & 11.1 & 45.4 & 0.4 & 0.1 & 100 & 54.1 & 4847 \\
\hline Stillbirth & 61.5 & 6.3 & 26.1 & 4 & 2 & 100 & 67.9 & 81 \\
\hline \multicolumn{9}{|l|}{ Age of mother at birth } \\
\hline$<20$ & 43.9 & 10.3 & 45.7 & 0.1 & 0 & 100 & 54.2 & 534 \\
\hline $20-34$ & 44.5 & 11.2 & 43.8 & 0.4 & 0.1 & 100 & 55.7 & 3391 \\
\hline $35-49$ & 38.8 & 10.8 & 49.3 & 0.7 & 0.4 & 100 & 49.6 & 1003 \\
\hline \multicolumn{9}{|l|}{ Birth order } \\
\hline 1 & 53.3 & 13.7 & 32.4 & 0.3 & 0.2 & 100 & 67.1 & 1051 \\
\hline $2-3$ & 46.3 & 10.6 & 42.8 & 0.1 & 0.1 & 100 & 56.9 & 1769 \\
\hline $4-5$ & 40.2 & 11.2 & 47.7 & 0.8 & 0.2 & 100 & 51.4 & 1161 \\
\hline $6+$ & 30.1 & 8.6 & 60.3 & 0.8 & 0.2 & 100 & 38.7 & 948 \\
\hline \multicolumn{9}{|l|}{ Residence } \\
\hline Rural & 31.6 & 6.6 & 61.2 & 0.5 & 0 & 100 & 38.2 & 3245 \\
\hline Urban & 65.8 & 19.5 & 14.1 & 0.2 & 0.4 & 100 & 85.3 & 1683 \\
\hline \multicolumn{9}{|l|}{ Education } \\
\hline None & 25.7 & 5.5 & 68 & 0.6 & 0.2 & 100 & 31.2 & 1678 \\
\hline Primary & 41.6 & 10.2 & 47.4 & 0.3 & 0.4 & 100 & 51.8 & 1102 \\
\hline Middle/JSS & 56.6 & 14.2 & 28.7 & 0.4 & 0 & 100 & 70.8 & 1797 \\
\hline Secondary+ & 64 & 23.8 & 12.1 & 0 & 0 & 100 & 87.9 & 350 \\
\hline \multicolumn{9}{|l|}{ Region } \\
\hline Ashanti & 54.5 & 13.2 & 31.3 & 0.8 & 0.2 & 100 & 67.7 & 922 \\
\hline Brong Ahafo & 43.1 & 13.6 & 42.8 & 0.4 & 0.1 & 100 & 56.7 & 564 \\
\hline Central & 42.6 & 15.9 & 41.2 & 0.3 & 0 & 100 & 58.5 & 479 \\
\hline Eastern & 47.9 & 10.4 & 41.4 & 0.1 & 0.1 & 100 & 58.3 & 567 \\
\hline Greater Accra & 55 & 24 & 20.1 & 0.5 & 0.4 & 100 & 79 & 470 \\
\hline Northern & 21.9 & 4.4 & 72.9 & 0.7 & 0.2 & 100 & 26.3 & 699 \\
\hline Volta & 35.3 & 5.8 & 58.7 & 0 & 0.1 & 100 & 41.2 & 451 \\
\hline Upper East & 45.8 & 0.9 & 53.4 & 0 & 0 & 100 & 46.6 & 225 \\
\hline Upper West & 40.2 & 1 & 58.8 & 0 & 0 & 100 & 41.2 & 152 \\
\hline Western & 43.8 & 9.4 & 45.8 & 0.5 & 0.5 & 100 & 53.2 & 400 \\
\hline \multicolumn{9}{|l|}{ Wealth quintile } \\
\hline Lowest & 24.3 & 2.7 & 72.7 & 0.2 & 0 & 100 & 27 & 1074 \\
\hline Second & 30.2 & 5.6 & 62.8 & 1.2 & 0.1 & 100 & 35.8 & 1061 \\
\hline Middle & 41.4 & 10.5 & 47.9 & 0.2 & 0 & 100 & 51.9 & 975 \\
\hline Fourth & 58.3 & 16.3 & 24.6 & 0.4 & 0.4 & 100 & 74.6 & 983 \\
\hline Highest & 68.6 & 23 & 8 & 0 & 0.4 & 100 & 91.6 & 835 \\
\hline Total & 43.3 & 11 & 45.1 & 0.4 & 0.2 & 100 & 54.3 & 4928 \\
\hline
\end{tabular}

found that while user-fee exemptions removed important financial barriers, they were insufficient to ensure equal access to maternal health service.

That inequities in skilled care services accessibility and utilization exist across different sub-population groups in Ghana is worrying. It is worrying because Ghana's user-fee exemption policy was intended to be universal. In practice, as our findings demonstrated, many women continue to deliver their babies at home or outside the provided government and non-government healthcare 
Table 7 Per cent distribution of most recent live or stillbirths in the five years preceding the survey by place of delivery according to religion and ethnicity*

\begin{tabular}{|c|c|c|c|c|c|c|c|c|c|c|c|c|}
\hline $\begin{array}{l}\text { Background } \\
\text { characteristic }\end{array}$ & $\begin{array}{l}\text { Own's } \\
\text { home }\end{array}$ & $\begin{array}{l}\text { Other } \\
\text { home }\end{array}$ & $\begin{array}{l}\text { Government } \\
\text { hospital/polyclinic }\end{array}$ & $\begin{array}{l}\text { Government } \\
\text { health center }\end{array}$ & $\begin{array}{l}\text { Government health } \\
\text { post/clinic }\end{array}$ & $\begin{array}{l}\text { Other public } \\
\text { health facility }\end{array}$ & $\begin{array}{l}\text { Private hospital } \\
\text { clinic }\end{array}$ & $\begin{array}{l}\text { Private maternity } \\
\text { home }\end{array}$ & $\begin{array}{l}\text { Other private } \\
\text { health facility }\end{array}$ & Other & Total & $\begin{array}{l}\text { Number } \\
\text { of women }\end{array}$ \\
\hline \multicolumn{13}{|l|}{ Religion } \\
\hline Catholic & 39.3 & 5.3 & 30 & 9.4 & 4.3 & 0.1 & 6.8 & 3.9 & 0.4 & 0.4 & 100 & 694 \\
\hline Protestant & 30 & 1.2 & 41.2 & 13.8 & 3.8 & 0 & 6.2 & 2.5 & 0 & 1.2 & 100 & 80 \\
\hline Methodist & 28.7 & 5.5 & 35.9 & 10.1 & 4.6 & 0 & 9.5 & 5.2 & 0 & 0.6 & 100 & 348 \\
\hline Presbyterian & 28.4 & 6.6 & 38.2 & 9.5 & 4.4 & 0.3 & 7.3 & 5.3 & 0 & 0 & 100 & 317 \\
\hline $\begin{array}{l}\text { Pentecostal/ } \\
\text { Charismatic }\end{array}$ & 25.4 & 8 & 36.3 & 9.5 & 4 & 0.1 & 9.6 & 5.9 & 0.9 & 0.3 & 100 & 1404 \\
\hline Other Christian & 31.3 & 7.1 & 31.1 & 11.1 & 5.5 & 0 & 8.1 & 5.1 & 0.1 & 0.5 & 100 & 836 \\
\hline Moslem & 47.5 & 2.5 & 27.6 & 8.4 & 2.5 & 0 & 7.3 & 3.9 & 0.1 & 0.3 & 100 & 895 \\
\hline $\begin{array}{l}\text { Traditional/ } \\
\text { Spiritualist }\end{array}$ & 76.3 & 5.3 & 6.3 & 6.8 & 2.9 & 0 & 1 & 0.5 & 0 & 1 & 100 & 207 \\
\hline No Religion & 65.2 & 5.5 & 10.6 & 9.6 & 4.4 & 0 & 2.4 & 1.7 & 0 & 0.7 & 100 & 293 \\
\hline Other & 0 & 0 & 100 & 0 & 0 & 0 & 0 & 0 & 0 & 0 & 100 & 1 \\
\hline \multicolumn{13}{|l|}{ Ethnicity } \\
\hline Akan & 23.3 & 7.2 & 36.8 & 10.8 & 5.4 & 0 & 9.7 & 5.9 & 0.5 & 0.4 & 100 & 2.248 \\
\hline Ga/Dangme & 21.5 & 11.4 & 37.1 & 8.7 & 3.7 & 0.2 & 9.2 & 6.4 & 1.2 & 0.5 & 100 & 404 \\
\hline Ewe & 43.5 & 5.4 & 28.3 & 8.2 & 2.8 & 0 & 6.4 & 5 & 0.2 & 0.3 & 100 & 644 \\
\hline Guan & 57.1 & 9.2 & 19.3 & 2.5 & 2.5 & 0 & 5.9 & 1.7 & 0 & 1.7 & 100 & 119 \\
\hline Mole-Dagbani & 60.7 & 2.4 & 20.3 & 7.5 & 2.6 & 0 & 3.8 & 2.2 & 0 & 0.5 & 100 & 547 \\
\hline Grussi & 59.8 & 0.4 & 22.4 & 8.5 & 2.8 & 0 & 5.7 & 0.4 & 0 & 0 & 100 & 246 \\
\hline Gruma & 66.8 & 2.9 & 15.5 & 9.3 & 1.5 & 0.3 & 2.6 & 0.9 & 0 & 0.3 & 100 & 343 \\
\hline Hausa & 12.9 & 3.2 & 59.7 & 3.2 & 0 & 0 & 12.9 & 8.1 & 0 & 0 & 100 & 62 \\
\hline Other & 44.3 & 4.5 & 23.5 & 11.9 & 5 & 0 & 6.5 & 3.7 & 0.2 & 0.4 & 100 & 463 \\
\hline Total & 37 & 5.9 & 30.5 & 9.6 & 4.1 & 0.1 & 7.6 & 4.6 & 0.4 & 0.4 & 100 & 5076 \\
\hline
\end{tabular}

*Total includes 148 women with missing information on place of delivery. 
Table 8 Per cent distribution of most recent live or stillbirth in the five years preceding the survey by whether delivery was caesarean section according to religion and ethnicity*

\begin{tabular}{|c|c|c|c|c|}
\hline Background characteristic & Delivery by CS & Other & Total & Number of births \\
\hline \multicolumn{5}{|l|}{ Religion } \\
\hline Catholic & 12.9 & 87.1 & 100 & 380 \\
\hline Protestant & 11.1 & 88.9 & 100 & 54 \\
\hline Methodist & 11.6 & 88.4 & 100 & 225 \\
\hline Presbyterian & 14.5 & 85.5 & 100 & 207 \\
\hline Pentecostal/Charismatic & 12.5 & 87.5 & 100 & 928 \\
\hline Other Christian & 12.4 & 87.6 & 100 & 510 \\
\hline Moslem & 10.9 & 89.1 & 100 & 440 \\
\hline Traditional/Spiritualist & 5.7 & 94.3 & 100 & 35 \\
\hline No Religion & 9.6 & 90.4 & 100 & 83 \\
\hline Other & 0 & 100 & 100 & 1 \\
\hline \multicolumn{5}{|l|}{ Ethnicity } \\
\hline Akan & 12.4 & 87.6 & 100 & 1551 \\
\hline Ga/Dangme & 12.6 & 87.4 & 100 & 269 \\
\hline Ewe & 16 & 84 & 100 & 326 \\
\hline Guan & 10.5 & 89.5 & 100 & 38 \\
\hline Mole-Dagbani & 13.3 & 86.7 & 100 & 195 \\
\hline Grussi & 7.2 & 92.8 & 100 & 97 \\
\hline Gruma & 5.8 & 94.2 & 100 & 103 \\
\hline Hausa & 11.5 & 88.5 & 100 & 52 \\
\hline Other & 9.1 & 90.9 & 100 & 231 \\
\hline Total & 12.2 & 87.8 & 100 & 2862 \\
\hline
\end{tabular}

*Total excludes 2066 women with missing information on delivery by CS.

facilities without skilled care. The discrepancies in access to and use of maternal health services among women from different socio-economic backgrounds that we observed in our study should not be overlooked.

Our findings indicate important spatial inequities in access to and use of all components of maternal health services. For instance, 38\% more women in the best performing geographic region (Central Region) than the worst (Upper East Region), accessed and used all skilled ANC, DC, PNC services in the five years preceding the survey. This utilisation differential could be related to a number of factors, including differences in coverage of maternal health services. In fact, those women most likely to give birth at home without skilled attendance or with a TBA came from geographic regions such as Upper West and East, Northern and Volta that generally suffer the worse forms of multiple deprivation including wealth, knowledge and health [44]. This deprivation in and of itself could put women from these impoverished regions in a particularly disadvantaged position in terms of their ability to get formal education, earn a decent income and access healthcare. In terms of policy, our findings here would indicate the need to direct more efforts and interventions towards those regions where access levels are low.

Wealth-related inequities were also documented. More women (53\%) in the highest wealth quintile than women in the lowest accessed and used all components of skilled ANC, DC, PNC services in the five years preceding the survey. In general, skilled attendance at birth, delivery in a health facility, use of caesarean section (CS) during childbirth, and post-delivery services all indicated gradients that were in favour of the wealthiest. Less surprisingly, women in the poorest wealth quintile used more unskilled home delivery services offered by TBAs. In the context of Ghana where maternal health services are provided free at the point of delivery, poverty, unavailability of maternal health services, high transportation costs, difficulties with arranging appropriate transportation to seek care, as well as other opportunity and social costs associated with maternal health seeking, might explain the rich-poor gap in service accessibility and utilisation. Addressing the rich-poor gap in access to maternal health services could therefore be essential for achieving the maternal health MDG targets.

Education-related inequities in the rate of access and use of maternal health services were also observed. For 
Table 9 Per cent distribution of postnatal care provider among women with a live or stillbirth in the five years preceding the survey

\begin{tabular}{|c|c|c|c|c|c|c|c|c|c|c|c|c|c|}
\hline $\begin{array}{l}\text { Background } \\
\text { characteristic }\end{array}$ & $\begin{array}{l}\text { Received } \\
\text { PNC }\end{array}$ & $\begin{array}{l}\text { Received PNC from } \\
\text { medically trained } \\
\text { provider }\end{array}$ & Doctor & $\begin{array}{l}\text { Nurse/midwife/ } \\
\text { auxiliary midwife }\end{array}$ & $\begin{array}{l}\text { Trained } \\
\text { traditional } \\
\text { birth } \\
\text { attendant }\end{array}$ & $\begin{array}{l}\text { Untrained } \\
\text { traditional } \\
\text { birth } \\
\text { attendant }\end{array}$ & $\begin{array}{l}\text { Relative/ } \\
\text { Friend }\end{array}$ & Other & No one & $\begin{array}{l}\text { Missing } \\
\text { provider } \\
\text { information }\end{array}$ & $\begin{array}{l}\text { Missing PNC } \\
\text { information }\end{array}$ & Total & $\begin{array}{l}\text { Number } \\
\text { of births }\end{array}$ \\
\hline \multicolumn{14}{|l|}{ Birth outcome } \\
\hline Live Birth & 75.9 & 54.8 & 12.9 & 41.8 & 11 & 4.7 & 5.2 & 0.2 & 23.9 & 0 & 0.2 & 100 & 4847 \\
\hline Stillbirth & 73.3 & 61.9 & 35.8 & 26.1 & 5.9 & 0 & 5.5 & 0 & 24.8 & 0 & 2 & 100 & 81 \\
\hline \multicolumn{14}{|c|}{ Place of delivery } \\
\hline Health facility & 87 & 86.5 & 23.6 & 63 & 0.5 & 0 & 0 & 0 & 12.8 & 0 & 0.2 & 100 & 2675 \\
\hline Elsewhere & 62.7 & 17.3 & 1.1 & 16.3 & 23.5 & 10.1 & 11.3 & 0.3 & 37.2 & 0.1 & 0.1 & 100 & 2244 \\
\hline \multicolumn{14}{|c|}{$\begin{array}{l}\text { Had problems before, } \\
\text { during or after delivery }\end{array}$} \\
\hline No & 74.9 & 52.5 & 11.1 & 41.4 & 11.6 & 5.2 & 5.3 & 0.1 & 25 & 0.1 & 0.1 & 100 & 3908 \\
\hline Yes & 80 & 64.3 & 21.8 & 42.5 & 8.5 & 2.2 & 4.8 & 0.2 & 19.9 & 0 & 0.1 & 100 & 1011 \\
\hline \multicolumn{14}{|l|}{ Residence } \\
\hline Rural & 72.2 & 43.4 & 7.9 & 35.6 & 14.9 & 6.5 & 7.1 & 0.2 & 27.7 & 0.1 & 0.1 & 100 & 3245 \\
\hline Urban & 82.7 & 76.9 & 23.7 & 53.2 & 3.4 & 0.9 & 1.4 & 0 & 16.6 & 0 & 0.6 & 100 & 1683 \\
\hline \multicolumn{14}{|l|}{ Region } \\
\hline Ashanti & 79.9 & 71 & 17.3 & 53.8 & 5.9 & 1.3 & 1.2 & 0.4 & 20 & 0 & 0.2 & 100 & 922 \\
\hline Brong Ahafo & 90.9 & 63.4 & 8.2 & 55.1 & 14.8 & 4.5 & 8.2 & 0 & 8.7 & 0 & 0.3 & 100 & 564 \\
\hline Central & 92.8 & 64.2 & 9.5 & 54.7 & 22.7 & 3.9 & 2 & 0 & 7 & 0 & 0.2 & 100 & 479 \\
\hline Eastern & 66.1 & 57.4 & 14.6 & 42.8 & 5.7 & 1.5 & 1.3 & 0.2 & 33.4 & 0 & 0.4 & 100 & 567 \\
\hline Greater Accra & 64.2 & 56.3 & 25.7 & 30.6 & 4.5 & 1.5 & 1.9 & 0 & 35.2 & 0 & 0.5 & 100 & 470 \\
\hline Northern & 79.6 & 26.1 & 6.6 & 19.5 & 15.5 & 18.2 & 19.2 & 0.3 & 20.2 & 0.3 & 0.2 & 100 & 699 \\
\hline Volta & 56 & 38.5 & 12 & 26.5 & 9.2 & 1.1 & 7.1 & 0 & 43.7 & 0 & 0.3 & 100 & 451 \\
\hline Upper East & 77.1 & 66.8 & 4.7 & 62.1 & 10.3 & 0 & 0 & 0 & 22.9 & 0 & 0 & 100 & 225 \\
\hline Upper West & 61.2 & 56.4 & 2 & 54.4 & 4.8 & 0 & 0 & 0 & 38.8 & 0 & 0 & 100 & 152 \\
\hline Western & 72.7 & 50.6 & 21.6 & 29 & 14.9 & 5.8 & 1.4 & 0 & 26.8 & 0.1 & 0.5 & 100 & 400 \\
\hline \multicolumn{14}{|l|}{ Wealth quintile } \\
\hline Lowest & 65.8 & 35 & 5.4 & 29.7 & 12.3 & 8.4 & 9.7 & 0.2 & 34.2 & 0.1 & 0 & 100 & 1074 \\
\hline Second & 73.8 & 41 & 6.4 & 34.6 & 17 & 6.8 & 8.6 & 0.3 & 26 & 0.1 & 0.2 & 100 & 1061 \\
\hline Middle & 77.3 & 54.1 & 8.6 & 45.4 & 15.6 & 4.1 & 3.6 & 0 & 22.5 & 0 & 0.2 & 100 & 975 \\
\hline Fourth & 80.2 & 69.8 & 20.2 & 49.6 & 6.3 & 1.6 & 2.3 & 0.2 & 19.2 & 0 & 0.6 & 100 & 983 \\
\hline Highest & 84.3 & 81.5 & 29.6 & 51.9 & 1.7 & 0.9 & 0.3 & 0.1 & 15.1 & 0 & 0.5 & 100 & 835 \\
\hline Total & 75.8 & 54.9 & 13.3 & 41.6 & 11 & 4.6 & 5.2 & 0.1 & 23.9 & 0 & 0.3 & 100 & 4928 \\
\hline
\end{tabular}


Table 10 Per cent distribution of whether postnatal care was received among women with a live or stillbirth in the five years preceding the survey, according to religion and ethnicity*

\begin{tabular}{|c|c|c|c|c|}
\hline Background characteristic & Obtained PNC & No PNC & Total & Number of births \\
\hline \multicolumn{5}{|l|}{ Religion } \\
\hline Catholic & 77.7 & 22.3 & 100 & 694 \\
\hline Protestant & 78.8 & 21.2 & 100 & 80 \\
\hline Methodist & 85.3 & 14.7 & 100 & 346 \\
\hline Presbyterian & 72.9 & 27.1 & 100 & 317 \\
\hline Pentecostal/charismatic & 77.5 & 22.5 & 100 & 1402 \\
\hline Other Christian & 75.2 & 24.8 & 100 & 836 \\
\hline Moslem & 77.5 & 22.5 & 100 & 893 \\
\hline Traditional/spiritualist & 65.7 & 34.3 & 100 & 207 \\
\hline No religion & 63.1 & 36.9 & 100 & 293 \\
\hline Other & 1 & 0 & 100 & 1 \\
\hline \multicolumn{5}{|l|}{ Ethnicity } \\
\hline Akan & 81.8 & 18.2 & 100 & 2244 \\
\hline Ga/Dangme & 66.6 & 33.4 & 100 & 404 \\
\hline Ewe & 66.5 & 33.5 & 100 & 644 \\
\hline Guan & 81.4 & 18.6 & 100 & 118 \\
\hline Mole-Dagbani & 78.3 & 21.7 & 100 & 548 \\
\hline Grussi & 67.1 & 32.9 & 100 & 246 \\
\hline Gruma & 66.8 & 33.2 & 100 & 343 \\
\hline Hausa & 87.1 & 12.9 & 100 & 62 \\
\hline Other & 76.6 & 23.4 & 100 & 461 \\
\hline Total & 76.1 & 23.9 & 100 & 5070 \\
\hline
\end{tabular}

*Total includes 142 women with missing information on PNC.

example, $48 \%$ more women with at least secondary education than those with no formal education accessed and used all skilled ANC, DC, PNC services. Indeed, maternal education has been found to be positively associated with access and use of many of the elements of skilled maternity care such as delivering in a hospital $[45,46]$. Influences of maternal education on maternal healthcare access can be effected in several ways, including improving the ability of women of reproductive age to produce good maternal health outcomes without even relying on health services by influencing their reproductive behaviours such as contraceptive use, increasing women's use of maternity care services through improved knowledge, attitude and practice, empowering women to be able to leverage decision-making power regarding reproductive choices and access to birth services within the household and community [47]. Our findings here would therefore indicate the need for improvement in women's education up to at least secondary level in order to bridge the equity gap and improve access to essential maternal health services.

We also observed important urban-rural inequality in access to and use of maternal health interventions. For instance, $40 \%$ more urban women than rural women accessed and used all skilled ANC, DC, PNC services in the five years preceding the survey. This is consistent with previous studies in Ghana [48]. It might be difficult in the current study to identify the exact mechanisms by which rural-urban inequities are effected. However, we believe these access inequities could partly be linked to a number of supply-side factors, whereby there is urbanbias in the availability of, quality of, and ease of access to, maternal health services. This is more likely to be so because Ghana is known to have marked rural-urban disparity in health infrastructure [49]. It could also partly be because there is a high concentration of the bettereducated and economically empowered women in urban areas than in rural areas. As discussed above, both education and wealth could contribute to enabling more urban women than rural women, to access maternal health services. In this regard, we think the practice of concentrating health facilities and resources in urban areas in Ghana need to change to ensure equity in access and to mitigate the distance barrier for rural women. In rural areas, we recommend the establishment of more maternal health clinics within reasonable distance to facilitate equitable access. 
Our study has also revealed important access inequities between different religious groups. For example, whereas $15 \%$ of Presbyterian Christians accessed and used CS services, only $6 \%$ of women professing traditional/spiritualist religion did for their last birth in the five years preceding the survey. Moslem women also accessed and used CS services less compared with their Christian counterparts. That differences in religious affiliation influenced accessibility to, and utilisation of maternity care services in Ghana bear resonance with other previous studies. In Ghana, Addai [46] found that the range for consultation of a health worker for prenatal care among religious groups was 12.8 points, from 10.3\% among women of traditional African religious orientation to $23.1 \%$ among Catholic and Protestant women. Gyimah et al [48] also found that Moslem and Traditional women were less likely to use maternal health services in Ghana compared with Christians. Elsewhere in India one study also found that Muslim women were less likely to use reproductive, sexual, and maternal health services compared with Christians [50]. It is difficult to tell from our study how issues in Muslim culture or Traditional African religious beliefs act as barriers to use of maternal services; neither can we exactly explain why Catholic women for example, patronise more maternal health services than Muslim women or women with Traditional African religious orientation. For this reason, we support Gyimah et al [48] call for more qualitative research into aspects of religious affiliation that discourage access and use of maternal health services.

Lastly, fewer women from majority ethnic groups such as the Akan (23\%) and Ga/Dangme (22\%) were found to have given birth at home compared with women from minority ethnic groups such as the Ewe (44\%), Guan (57\%), Grussi (60\%), Mole-Dagbani (61\%) and Gruma (66\%). Being in a minority ethnic group has been found to be a barrier to access to and use of maternal health services [51]. One previous study in Ghana found that while almost equal proportions of women of the GaAdangbe, Fante and Akan ethnic groups used the hospital or health facility as place of delivery, lower proportions are observed for women of Ewe, Guan, Gruma and other minority ethnic backgrounds [46]. Indigenous women in Guatemala [52] and Mexico [53], and ethnic minorities in China [54] have been found to be less likely to have skilled attendance at delivery.

It is not possible to say from our study why minority ethnic women had less access to care compared with majority ethnic women, neither are we able to determine whether belonging to a majority group such as the Akan or a minority group such as the Gruma automatically implies more access and less access respectively. We believe that more qualitative research is needed to explore these issues. We however think these access differentials could be explained by the fact that women from minority ethnic groups are more likely to suffer discrimination and abuse upon entry into the healthcare system. For this reason, the social imperatives for such women to avoid the formal healthcare system simply are powerful. Elsewhere in Bangladesh, Schuler and colleagues [25] have documented a similar phenomenon. Naturally, differences in discrimination introduces differential costs of accessing care for different people, and this violates the second requirement of equity of access which argues for a situation in which individuals or groups face equal or equivalent access and costs of utilization for equal or equivalent needs. In this regard, it might be useful for policymakers in Ghana to take urgent steps to develop comprehensive need-based targeting and resource allocation formula that can target more resources and services towards minority populations.

\section{Methodological considerations}

Our findings and recommendations in this paper should be read against the backdrop of certain potential limitations. Our study design could potentially have made it impossible to isolate the effects (positive or negative) of the user-fee exemption policy on access and inequity in access. Ideally, a pre-post evaluation design would have been most appropriate for investigating the impact of implementing the exemption policy on skilled care services accessibility and utilization in Ghana. In particular, pursuing a counter-factual analysis would have been the best approach in determining whether the policy actually increased access and improved equity in access and use of services. That is, what would have happened to access and equity in the absence of the policy during the period under consideration (2003-2007)? However, because the policy was implemented nation-wide, such an analysis was not feasible as there are no appropriate comparison groups against which a comparative assessment can be made. Unfortunately, both the design and remits of this research failed to extend to an evaluation and statistical estimation or quantification of how much of either the increases in overall utilisation levels or the differences in utilisation among different groups is directly attributable to the fee exemption policy.

Also, secondary data come with its own strengths and weaknesses, and the GMHS data we used is no exception. At the commencement of our research, this data set was one of the best readily available, and up-to-date databases on maternal healthcare access in Ghana. The main strengths of the data are the large sample size and its representativeness of the population. Both of the two attributes are known to increase precision of estimates of study sub-groups [55]. However, given that the data is almost six years old, its relevance for capturing current access and utilisation levels and patterns may be diminished. 


\section{Conclusion}

Like many health policies that aim to address financial barriers to healthcare access, Ghana's user-fee exemption policy was based on an assumption that all women would avail themselves to access and use maternal health services if only these services became more affordable [18]. The findings in this paper suggest that although removing userfees has the potential to improve access to skilled care, it is neither sufficient nor appropriate for eliminating inequities in access in some contexts. Our findings and discussion clearly indicate that differences in women's socio-economic status, as represented by differentials in educational attainment, wealth, type of residence, geographical region, religious affiliation, and ethnic background play a crucial role in the continued practice of maternal health services under-utilisation, and unequal access to skilled care and homebirth. That differences in women's sociodemographic attributes influence their ability to access and use maternal health services in Ghana clearly violates one of the fundamental requirements for equity of access, namely that non-medical or non-biological features of individuals or groups should not determine their access to healthcare. At the same time, most of these socioeconomic status variables lie outside the confines of the healthcare system. This suggests that if equity in access to maternal health is to be achieved in Ghana, the policy debates on user-fees removal ought to proceed beyond increases in service utilisation towards exploring who continues to remain excluded from access to maternal care services following user-fee exemption, and how best to address the multiplicity of access and utilisation barriers other than money that might prevent some women from seeking care. In this regard, we believe a concerted multisectorial approach is needed to tackle the social determinants of health as well as address the wider issue of economic, social and political disadvantage, including raising the educational attainment and living conditions of disadvantaged women, improving the availability, distribution and quality of physical health infrastructure, and increasing the quantity and capacity of human resources for maternal health.

\section{Competing interests}

The authors declare that they have no competing interests.

\section{Authors' contributions}

JKG conceived the study, JKG, MP and RF contributed to the design, JKG and EO collected the data, JKG, OE, MP and RF contributed to the data analysis, JKG and EO drafted the manuscript, JKG, EO, MP, RF reviewed the draft. All authors read and approved the final draft.

\section{Acknowledgement}

This research was funded by a Wellcome Trust Doctoral Studentship as part of a Wellcome Trust Enhancement Award (Number 087285) to the Ethox Centre, Nuffield Department of Population Health, University of Oxford. The work of the Ethox Centre in Global Health Bioethics is supported by a Wellcome Trust Strategic Award (096527). However, the funder played no role in the design, data collection, analysis, interpretation of data, writing of the manuscript, and the decision to submit the manuscript for publication. We also acknowledge the support of the Ghana Statistical Service, which generously granted us access to the data we used in this paper.

\section{Author details}

${ }^{1}$ The Ethox Centre, Nuffield Department of Population Health, University of Oxford, Rosemary Rue Building, Old Road Campus, Headington, Oxford OX3 7LF, UK. ${ }^{2}$ Nuffield Department of Population Health, University of Oxford, Rosemary Rue Building, Old Road Campus, Headington, Oxford OX3 7LF, UK ${ }^{3}$ Department of Community Health, School of Medical Sciences, Kwame Nkrumah University of Science and Technology, Kumasi, Ghana.

Received: 6 July 2014 Accepted: 29 September 2014

Published online: 01 November 2014

\section{References}

1. Ridde $V$, Diarra $A$ : A process evaluation of user fees abolition for pregnant women and children under-five years in Niger (West Africa). BMC Health Serv Res 2009, 9:89.

2. Witter S, Adjei S, Armar-Klemesu M, Graham W: Providing free maternal healthcare: ten lessons from evaluation of the national delivery exemption policy in Ghana'. Global Health Action 2009, 10:2.

3. Zere E, Tumusiime P, Walker O, Kirigia J, Mwikisa C, Mbeeli T: Inequities in utilization of maternal health interventions in Namibia: implications for progress towards MDG 5 targets. Int J Equity Health 2010, 9:16.

4. Campbell OM, Graham WJ: Strategies for reducing maternal mortality: getting on with what works. Lancet 2006, 368(9543):1284-1299.

5. Zere E, Oluwole D, Kirigia JM, Mwikisa CN, Mbeeli T: Inequities in skilled attendance at birth in Namibia: a decompositional analysis. Int J Equity Health 2011, 11:36.

6. Starrs A: Safe motherhood initiative: 20 years and counting. Lancet 2006, 368:1130-1132.

7. Ronsmans C, Graham W: Maternal mortality: who, when, where and why? Lancet 2006, 368:1189-1200.

8. Essendi H, Mills S, Fotso J: Barriers to formal emergency obstetric care services' utilization. J Urban Health 2010, 88(2):S356-s369.

9. Abor PA, Abekah-Nkrumah G, Sakyi K: The socio-economic determinants of maternal health care utilization in Ghana. Int J Soc Econ 2011, 38(7):628-648.

10. World Health Organization: Trends in Maternal Mortality: 1990 to 2010: Estimates Developed by WHO, UNICEF, UNFPA and the World Bank. Geneva: World Health Organization; 2012.

11. Witter S, Arhinful KD, Kusi A, Zakariah-Akoto S: The experiences of Ghana in implementing a user fee exemption policy to provide free delivery care. Reprod Health Matter 2007, 15(30):61-71.

12. Bosu WK, Bell SJ, Armar-Klemesu M, Tornui AJ: Effect of delivery care user fee exemption policy on institutional maternal deaths in the Central and Volta Regions of Ghana. Ghana Med J 2007, 41(3):118-123.

13. Witter S: An Unnecessary Evil? User fees for Health Care in Low-Income Countries. London: Save the Children; 2005.

14. Ministry of Health: National Consultative Meeting on the Reduction of Maternal Mortality in Ghana: Partnership for Action. Accra, Ghana: Ministry of Health, Policy Planning Monitoring and Evaluation Department; 2008.

15. Sidney K, Diwan V, El-Khatib Z, de Costa A: India's JSY cash transfer program for maternal health: who participates and who doesn't a report from Ujjain district. Reprod Health 2012, 9(1):2-8.

16. Witter S, Dieng T, Mbengue D, Moreira I, De Brouwere V: The national free delivery and caesarean policy in Senegal: evaluating process and outcomes. Health Pol Plann 2010, 25:384-392.

17. De Allegri M, Ridde V, Louis RV, Sarker M, Tiendrebéogo J, Yé M, Müller O, Jahn A: Determinants of utilization of maternal care services after the reduction of user fees: a case study from rural Burkina Faso. Health Pol 2010, 10:10.

18. Ridde V, Kouanda S, Bado A, Bado N, Haddad S: Reducing the medical cost of deliveries in Burkina Faso is good for everyone, including the poor. Plos One 2012, 7(3):e33082

19. Smilth K, Sulzbach S: Community-based health insurance and access to maternal health services: evidence from three West African countries. Soc Sci Med 2008, 66(12):2460-2473.

20. El-Khoury M, Hatt L, Gandaho T: User fee exemptions and equity in access to caesarean sections: an analysis of patient survey data in Mali. Int J Equity Health 2012, 11(49):1-7. 
21. Kruk ME, Prescott MR, Galea S: Equity of skilled birth attendant utilization in developing countries: financing and policy determinants. Am J Public Health 2008, 98(1):142-147.

22. Obare F, Warren C, Njuki R, Abuya T, Sunday J, Askew I, Bellows B: Community-level impact of the reproductive health vouchers programme on service utilization in Kenya. Health Pol Plann 2012, 28(2):165-175.

23. Ensor T: Cost Sharing System for Alleviating Financial Barriers to Delivery Care: Review of the Proposed Scheme. London: Options; 2005.

24. Borghi J, Ensor T, Neupane BD, Tiwari S: Financial implications of skilled attendance at delivery in Nepal. Tropical Med Int Health 2006, 11(2):228-237.

25. Schuler SR, Bates LM, Islam MK: Paying for reproductive health services in Bangladesh: intersections between cost, quality and culture. Health Pol Plann 2002, 17(3):273-280.

26. De Brouwere V, Richard F, Witter S: Access to maternal and perinatal health services: lessons from successful and less successful examples of improving access to safe delivery and care of the newborn. Trop Med Int Health 2010, 15(8):901-909.

27. Jehan K, Sidney K, Smith H, de Costa A: Improving access to maternity services: an overview of cash transfer and voucher schemes in South Asia. Reprod Health Matter 2012, 20(39):142-154.

28. Nanda P: Gender dimensions of user fees: implications for women' utilization of health care. Reprod Health Matter 2002, 10:20.

29. Dzakpasu S, Soremekun S, Manu A, Asbroek G, Tawiah C, Hurt L, Fenty J, Owusu-Agyei S, Hill Z, Campbell OMR, Kirkwood RB: Impact of free delivery care on health facility delivery and insurance coverage in Ghana's Brong Ahafo region. PLoS One 2012, 7(11):e49430.

30. Ghana Statistical Service: Ghana Population and Housing Census 2010. Accra: Ghana Statistical Service; 2012.

31. Zere E, Kirigia MJ, Duale S, Akazili J: Inequities in maternal and child health outcomes and interventions in Ghana. BMC Public Health 2012, 12:252.

32. World Health Organization: World Health Report. Geneva: World Health Organization; 2010.

33. Macinko AJ, Starfield B: Annotated bibliography on equity in health, 1980-2001. Int J Equity Health 2002, 1(1):1-20.

34. van Doorslaer E, Wagstaff A, van der Burg H, Christiansen T, De Graeve D, Duchesne I, Gerdtham UG, Gerfin M, Geurts J, Gross L, Hakkinen U, John J, Klavus J, Leu RE, Nolan B, O'Donnell O, Peopper C, Puffer F, Schellhorn M, Sundberg G, Winkelhake O: Equity in delivery of healthcare in Europe and the US. J Health Econ 2000, 19:553-583.

35. Guliani H, Sepehri A, Serieux J: What impact does contact with the prenatal care system have on women's use of facility delivery? Evidence from low-income countries. Soc Sci Med 2012, 74(12):1882-1890.

36. Yesuf $A E$, Colderon-Margalit R: Disparities in the use of antenatal care service in Ethiopia over a period of fifteen years. BMC Pregnancy Childbirth 2013 13:131.

37. Titaley $\mathrm{CR}$, Hunter $\mathrm{CL}$, Dibley MJ, Heywood P: Why do some women still prefer traditional birth attendants and home delivery? A qualitative study on delivery care services in West Java Province, Indonesia. BMC Pregnancy Childbirth 2010, 10(43):1-14.

38. Dumont A, de Bernis L, Bouvier-Colle MH, Bréart G: Caesarean section rate for maternal indication in sub-Saharan Africa: a systematic review. Lancet 2001, 358:1328-1334.

39. Wagstaff A, Bilger M, Sajaia Z, Lokshin M: Health Equity and Financial Protection: Streamlined Analysis with ADePT Software. World Bank: Washington, DC; 2011.

40. Houweling TA, Kunst AE, Mackenbach JP: Measuring health inequality in developing countries: does the choice of the indicator of economic status matter? Int J Equity Health 2003, 2:8.

41. Gulliford M: Equity and access to health care. In Access to Health Care. Edited by Gulliford M, Morgan M. London: Routledge; 2003.

42. Lagarde $\mathrm{M}$, Palmer $\mathrm{N}$ : The impact of user fees on health service utilization in low- and middle-income countries: how strong is the evidence? Bull World Health Organ 2008, 86:839-848.

43. Ridde V, Morestin F: A scoping review of the literature on the abolition of user fees in health care services in Africa. Health Pol Plann 2011, 26:1-11.

44. Ghana Statistical Service: Patterns and Trends of Poverty in Ghana 1991-2006. Accra: Ghana Statistical Service; 2007.

45. Say L, Raine R: A systematic review of inequalities in the use of maternal health care in developing countries: examining the scale of the problem and the importance of context. Bull World Health Organ 2007, 85:812-819.
46. Addai I: Determinants of use of maternal-child health services in rural Ghana. J Biosoc Sci 2000, 32:1-15.

47. Ahmed S, Creanga AA, Gillespie DG, Tsui AO: Economic status, education, and empowerment: implications for maternal health service utilization in developing countries. PLoS One 2010, 5(6):e11190.

48. Gyimah OS, Takyi BK, Addai I: Challenges to the reproductive-health needs of African women: on religion and maternal health utilization in Ghana. Soc Sci Med 2006, 62:2930-2944.

49. Asante $A D, Z$ wi $A B$ : Factors influencing resource allocation decisions and equity in the health system of Ghana. Publ Health 2009, 123:371-377.

50. Mishra V: Muslim/Non-Muslim differentials in fertility and family planning in India. Population \& Health Series, No. 112, East-west working papers, East-West Centre, Honolulu; 2004.

51. Reitmanova S, Gustafson DL: "They can't understand it": maternal health and care needs of immigrant Muslim women in St John's, Newfoundland. Matern Child Health J 2008, 12:101-111.

52. De Broe S: Diversity in the use of pregnancy-related care among ethnic groups in Guatemala. J Fam Plann Reprod Health Care 2005, 31(3):199-205.

53. Brentlinger PE, Sanchez-Perez HJ, Cedeno MA, Morales LG, Hernan MA Micek MA, Ford D: Pregnancy outcomes, site of delivery, and community schisms in regions affected by armed conflicts in Chiapas, Mexico. SoC Sci Med 2005, 61(5):1001-1014.

54. Short S, Zhang F: Use of maternal health services in rural china. Popul Stud 2004, 58(1):3-19.

55. Hofferth SL: Secondary data analysis in family research. J Marriage Fam 2005, 67(4):891-907.

\section{Submit your next manuscript to BioMed Central and take full advantage of:}

- Convenient online submission

- Thorough peer review

- No space constraints or color figure charges

- Immediate publication on acceptance

- Inclusion in PubMed, CAS, Scopus and Google Scholar

- Research which is freely available for redistribution 